\title{
The Relationship between High School Students' Participation in Sporting Activity and Personality Variables
}

\author{
By Miri Shachaf* \\ Yaacov J. Katz ${ }^{\dagger 1}$
}

\begin{abstract}
Research studies have indicated that participation in sporting activity can empower and enrich personality. The aim of the present study was to examine the relationship between the participation of male and female high school students in sporting activity and personality variables. The research hypotheses assumed that the level of participation in sporting activity of students would be related to differential levels of self-efficacy, self control and attribution style as well as to gender. 491 students from $10^{\text {th }}-12^{\text {th }}$ grades served as the research sample in the present study and were divided into three comparison groups: a competitive sport group; a non-competitive sport group; and a group that did not participate in any sporting activity. The students were administered a demographic questionnaire as well additional questionnaires designed to ascertain their levels of self-efficacy, self control and attribution style.The research findings indicate significant differences between the three research groups on the research variables. The students in the competitive sport group attained higher levels of self efficacy, selfcontrol and attribution style than students in the two other groups. No significant gender differences were found in the study with male and female students in each of the research groups reporting similar levels of self-efficacy, self-control and attribution style.The results of this study indicate that male and female students who participate in competitive sport are characterized by more positive personality characteristics than students who are not involved in that level of sporting activity. These results confirm previous studies that have indicated the advantage of participation in competitive sporting activity at the high school level regarding enhancement of psychological traits such as self-efficacy, self-control and attribution style.
\end{abstract}

Keywords: Attribution style; gender; self-efficacy; self control; sporting activity

\footnotetext{
*Lecturer, Givat Washington College of Education, Israel.

${ }^{\dagger}$ Professor, Bar-Ilan University, Israel.

${ }^{1}$ This paper is based on a Ph.D. research study conducted at the School of Education, Bar-Ilan University, Israel
} 


\section{Introduction}

Vital prerequisites for a competent competitive athlete are physical skills, that are either natural or acquired but these skills alone cannot ensure athletic competence. In addition to physical skills a competent athlete needs to be endowed with suitable personality traits that will allow him or her to endure long and difficult hours of strenuous physical training and psychological stress. The aims of this paper were a) to examine whether male and female high school students who participate in different levels of sporting activity develop and enhance different psychological traits that are congruent with their respective levels of sporting activity; and b) to address potential differences on personality traits between male and female participants in competitive sport.

\section{Theoretical Background}

Sport psychologists and sociologists have indicated that participation in competitive sport or even in non-competitive sporting activities by high school students contributes to the development of positive personality traits of the participants (Broh, 2002; Curtis , McTeer, \& White, 2003; Fejgin, 2001; Guest \& Schneider, 2003; Marsh, 1993). Shaffer \& Wittes (2006) indicated that participation in competitive sport enhances feelings of well-being among precollege male and female athletes. Donaldson \& Ronan (2006) confirmed that participation of adolescents in sport contributes to psychological wellbeing. Thus it appears that, in general terms, there is a relationship between participation in sporting activity and positive personality traits.

\section{Self-Efficacy}

Self-efficacy can be defined as the level of belief of the individual in his or her ability to perform a task or rise to a challenge (Bandura. 1977). Selfefficacy leads the individual to be confident about the achievement of a particular goal and eventually to the successful realization of that goal. Results of research studies have indicated that self-efficacy correlates with enhanced physical performance (Annesi et al, 2005; Petitpas et al, 2004). Feltz \& Magyar (2005) specifically indicated the contribution of self-efficacy to improved performance in competitive sport. Thus in the present study the relationship between self-efficacy and different levels of sporting activity will be examined.

\section{Self-Control}

Self-control is a trait that allows the individual to consciously direct and regulate behavior when attempting to achieve a particular goal (Goldfried \& Merbaum, 1973). An individual characterized by self-control has increased 
ability to command emotions and to focus on the planning and strategy necessary for goal attainment (Thoresen \& Mahoney, 1974).Recent research studies (Chiviacowsky \& Wulf, 2002; Wulf \& Toole, 1999) have indicated the positive relationship between self-control and superior performance. Dias, Cruz, \& Fonseca (2012) confirmed the relationship between performance in many braches of sport and self control of participants. In the present research the relationship between participation in sport at different levels and selfcontrol will be investigated.

\section{Attribution Style}

Weiner (1980) developed an attribution theory model which linked success or failure in the performance of a given task to internal or external attribution. According to Weiner internal attribution, whereby the individual attributes the results of his actions to him or her self, is a key variable related to successful performance. Lebedina-Manzoni (2004) indicated that successful students attributed their success to variables controlled by themselves whereas students who experienced failure attributed this failure to external variables not under their control. Fejgin $(1994 ; 2001)$ confirmed that competitive athletes who were successful in their particular branch of sport were significantly characterized by internal attribution of reasons for their success. Allen, Jones \& Sheffield (2009) confirmed the importance of internal attribution style as a significant variable related to superior sporting achievement. The present research study will address the relationship between attribution style and performance at different levels of sporting activity.

\section{Aim of the Study}

The aim of this study was to focus on the relationship between selfefficacy; self control and attribution style on the one hand and differential sporting activity on the other. The major research focus concentrated on the significance of self-efficacy, self-control and attribution for high school students undertaking different levels of sporting activity.

\section{Method}

\section{Participants}

The participants consisted of $49110^{\text {th }}-12^{\text {th }}$ grade students who studied in Israeli high schools and were divided into three comparative research groups. 170 students (107 males and 63 females) were in the competitive sport group and were active members of teams affiliated to the Israeli national high school basketball and volleyball premier leagues; 185 participants (79 males and 106 females) were in the in the non-competitive sport group and engaged in regular 
fitness programs in the school gym, working out at least twice a week in supervised one-hour sessions; and 106 students (32 males and 104 females) were in the group that did not participate in any organized sporting activity whatsoever.

\section{Research Instruments}

1. General Perceived Self-Efficacy Scale (GSE) - (Zeidner, Schwarzer \& Jerusalem, 1993) included ten items graded on a four point scale. The scale has been used in numerous research projects, where it has typically yielded internal consistencies ranging between $\alpha=.75-\alpha=.91$. Shachaf (2009) adapted the scale for use in an Israeli population and indicated reliability coefficients that ranged between $\alpha=.80-\alpha=91$

2. Self-Control Scale (SCS) - (Rosenbaum, 1980) included 36 items graded on a six point scale ranging from -3 to +3 with test - retest reliability that ranged between $\alpha=.78-\alpha=.84$. The questionnaire was adapted for use in the present study and tapped a general factor of self-control with a Cronbach alpha coefficient of $\alpha=.77$ (Shachaf, 2009).

3. Attribution Style Questionnaire - (Peterson et al, 1982) was adapted for use in the present study and consisted of six different hypothetical achievement related events, of which three had positive connotations, with the other three having negative connotations. All of the events were related to achievement in sporting activity. Students were required to indicate whether the main reason for the occurrence of every one of the hypothetical events depended on internal or external factors. Responses to the questionnaire were graded on a scale of 0 (external) - 7 (internal). The Cronbach alpha reliability of the questionnaire was $\alpha=0.75$.

4. Demographic Questionnaire - (Shachaf, 2009), specially compiled for the present study, was designed to classify the participants as members of one of comparison groups. The participants were also requested to state their gender and class level $\left(10^{\text {th }}, 11^{\text {th }}\right.$ or $12^{\text {th }}$ grade $)$.

\section{Procedure}

The students were administered the research questionnaires during a regular class lesson designated for this particular purpose. Each student was first required to complete a short demographic questionnaire, followed by the personality trait questionnaires. The students were informed about the general aims of the research study and were given an undertaking that their participation in the research would conform with research ethics and that all personal and identifying information regarding participation in the research study would remain anonymous. 


\section{Results}

One-way ANOVA tests were conducted in order to ascertain possible differences between the three research comparison groups on the three research factors, namely self-efficacy, self-control and attribution style. Results of the ANOVA procedures are presented in Table 1:

Table 1. Results of one-way ANOVAs for Comparative Groups on SelfEfficacy, Self-Control and Attribution Style $(n=491)$

\begin{tabular}{|c|c|c|c|c|c|c|c|c|}
\hline & \multicolumn{2}{|c|}{$\begin{array}{c}\text { Competitive } \\
\text { Sport }\end{array}$} & \multicolumn{2}{c|}{$\begin{array}{c}\text { Nompen } \\
\text { Sport }\end{array}$} & \multicolumn{2}{|c|}{$\begin{array}{c}\text { No Sporting } \\
\text { Activity }\end{array}$} & & \\
\hline Research Factors & M & SD & M & SD & M & SD & $\mathrm{F}(2,485)$ & $\eta^{2}$ \\
\hline Self efficacy & 3.38 & .39 & 3.29 & .43 & 3.21 & .41 & $6.89^{* *}$ & .03 \\
\hline Self control & 4.46 & 1.29 & 4.08 & 1.18 & 3.84 & 1.14 & $10.71^{* *}$ & .04 \\
\hline Attribution style & 5.85 & 1.02 & 5.78 & .90 & 5.59 & .98 & $3.18^{*}$ & .01 \\
\hline
\end{tabular}

${ }^{*} \mathrm{p}<.05 * * \mathrm{P}<.01$

Results of the one-way ANOVA procedures indicate significant main effects for self-efficacy, self-control and attribution style. Results of post-hoc Scheffe tests clarified that students in the competitive sport group had a significantly higher level of self-efficacy than students in the non-competitive sport group who in turn had a level of self-efficacy that was significantly higher than that of students in the group that did not participate in any sporting activity.

Findings of further post-hoc Scheffe tests intimated that on the self-control variable, members of the competitive sport group had a higher level of selfcontrol than either members of the non-competitive sport group or members of the group that did not partake in sporting activity. There were no significant differences on the self-control variable between non-competitive sport group members and students in the group that did not participate in sport at all.

Results of additional post-hoc Scheffe tests showed that there were significant differences on the attribution style factor between students in the competitive sport and the non-competitive sports groups on the one hand and members of the group that did not participate in sporting activity on the other However, no significant differences were found between members of the group that participated in competitive sport and students in the non-competitive sport group although the mean level of internal attribution style of those who participated in competitive sport was higher than that of students who participated in non-competitive sporting activity.

Further statistical analyses that examined possible gender differences indicated that scores attained on the three research variables by male and female students in the three respective comparison groups were similar. Thus no significant differences were evident between male and female students on the self-efficacy, self-control and attribution style variables. 


\section{Discussion}

In the present research possible personality trait differences between high school students who participated in different levels of sporting activity were examined. In addition, possible gender differences on the personality traits were investigated. Results of the study indicate that students who participated in competitive sport had significantly high levels of self-efficacy and selfcontrol than the students in the non-competitive sport group or in the group that did not participate in any sporting activity. In addition students in the competitive sport group as well as in the non-competitive sport group had a significantly more internal attribution style than students who did not participate in any sporting activity. Competitive sport athletes also had higher levels of internal attribution style than students who participated in noncompetitive sport although this difference was not statistically significant.

From the findings of the present research it is evident that participation in different levels of sporting activity at the high school age is significantly related to differential strength of personality traits. This result confirms research evidence provided by Curtis, McTeer \& White (2003), Howell, Miracle \& Rees (1989) and Marsh (1993) indicated that participation in competitive sport promotes the enhancement of personality traits. Different levels of commitment to sport seemingly differentially affect the strength of personality traits. Students who participate in competitive sport usually have an intensive training regimen, a well supervised nutrition program and are expected to perform well in their scholastic achievement despite time invested in competitive sport (Fejgin, 1994). Plowman \& Smith (2008) confirmed that the burden of physical investment made by athletes who participate in competitive sport toughens personality and Ring et al (2005) added that the mental strains experienced by competitive athletes contributes to the strengthening of personality traits.

Regarding the relationship between participation in different levels of sporting activity on the one hand and self-efficacy and self-control on the other Feltz \& Magyar (2005), Petitpas et al (2004) and van der Horest et al (2007) indicated that intensive sporting activity is associated with enhanced selfefficacy among athletes. Findings of additional research studies conducted by Cecchini et al (2007) as well as Harvey, Fagan \& Kassis (2003) testified to the fact that participation in competitive sport led to the development of increased self-control among athletes. On the issue of attribution style and participation in different levels of sport, Greenlees et al (2005) as well as Hamilton \& Jordan (2000) indicated that successful competitive athletes have higher levels of internal attribution style than those who participate in other forms of noncompetitive sport or sport for leisure purposes only.

Regarding gender results of this study indicated no significant differences between male and female students on the research factors of self-efficacy, selfcontrol and attribution style in the general research population. 


\section{Conclusion}

It appears that participation of both male and female high school students in competitive sport significantly contributes to a strengthening of personality traits in general, and as indicated in the results of the present study, promotes the enhancement of self-efficacy, self-control and internal attribution style. As Pine (2010) concurs, participation in competitive sporting activity contributes to the enhancement of psychological strengths. Thus high school student athletes can serve as positive role models for their peers.

\section{References}

Allen, M.S., Jones, M.V., \& Sheffield, D. (2009). 'Attribution, emotion and collective efficacy in sports teams.' Group Dynamics: Theory, Research, and Practice, 13: 205-217.

Annesi, J. J., Westcott, W. L., Faigenbaum, A. D., \& Unruh, J. L. (2005). 'Effects of 12- week physical activity protocol delivered by YMCA after school counselors (youth fit for life) on fitness and self- efficacy changes in 5-12 year old boys and girls.' Research Quarterly for Exercise and Sport, 76 (4): 468-476.

Bandura, A. (1977). 'Self- efficacy: toward a unifying theory of behavioral change.' Psychological Review, 84: 191-215.

Broh, B.A. (2002). 'Linking extracurricular programming to academic achievement: who benefits and why?' Sociology of Education, 75: 69-91.

Cecchini, J. A., Montero, J., Alonso, A., Izquierdo, M.,\& Contreras, O. (2007). 'Effects of personal and social responsibility on fair play in sports and self-control in school-aged youths.' European Journal of Sport Science, 7(4): 203-211.

Chiviacowsky, S., \& Wulf, G. (2002). 'Self-controlled feedback: does it enhance learning because performers get feedback when they need it?' Research Quarterly for Exercise and Sport, 73(4): 408- 415.

Curtis, J., McTeer, W., \& White, P. (2003). 'Do high school athletes earn more pay? Youth sport participation and earning as an adult.' Sociology of Sport Journal, 20: 60-76.

Dias, C., Cruz, J.F. \& Fonseca, A. (2012). 'The relationship between multidimensional competitive anxiety, cognitive threat appraisal, and coping strategies: A multisport study.' International Journal of Sport and Exercise Psychology, 10(1): 5265.

Donaldson, S. J. \& Ronan, K.R. (2006). 'The effects of sports participation on young adolescents' emotional well-being.' Adolescence, 41.162: 369-389.

Fejgin, N. (1994). 'Participation in high school competitive sport: a subversion of school mission or contribution to academic goals?' Sociology of Sport Journal, 11: 211-230.

Fejgin, N. (2001).' Participation in high school competitive sports: a subversion of school mission or contribution to academic goals?' In A. Yiannakis \& M. J. Melnick (eds.), Contemporary issues in sociology of sport, 95-108. Champaign, IL: Human Kinetics. 
Feltz, D. L., \& Magyar, T. M. (2005). 'Self- efficacy and adolescents in sport and physical activity.' In F. Pajares \& T. Urdan (eds.), Self- efficacy beliefs and adolescent development and education, 161-179. Greenwich, CT: Information Age Publishing.

Greenlees, I., Lane, A., Thelwell, R., Holder, T. \& Hobson, G. (2005). 'Team-referent attributions among sport performers.' Research Quarterly for Exercise and Sport, 76(4): 477-87.

Goldfried, M. R., \& Merbaum, M. (1973). Behavior change through self control. Oxford: Holt, Rinehart \& Winston.

Guest, A., \& Schneider, B. (2003). 'Adolescents' extracurricular participation in context: the mediating effects of school, communities, and identity.' Sociology of Education, 76(2): 89-109.

Hamilton, P.R. \& Jordan, J. S. (2000). 'Most successful and least successful performances: Perceptions of causal attributions in high school track athletes.' Journal of Sport Behavior, 23(3): 245-254.

Harvey, W. J., Fagan, T., \& Kassis, J. (2003). 'Enabling students with ADHD to use self-control in physical activities.' Palaestra, 19(3): 32-35.

Howell, F. M., Miracle, A. W., \& Rees, C. R. (1989). 'Do high school athletics pay? the effect of varsity participation on socioeconomic attainment.' Sociology of Sport Journal, 1: 15-25.

Lebedina-Manzoni, M. (2004). To what students attribute their academic success and unsuccess. Education, 124(4), 699.

Marsh, H. W. (1993). 'The effects of participation in sport during the last two years of high school.' Sociology of Sport Journal, 10: 18-43.

Peterson, C., Semmel, A., von Baeyer C., Abramson, L. Y., Metalsky, G. I., \& Seligman, M. E. P. (1982). 'The Attributional Style Questionnaire.' Cognitive Therapy Research, 6: 287-299.

Petitpas, A. J., van Raalte, J. L., Cornelius, A. E., \& Presbrey, J. (2004). 'A life skills development program for high school student athletes.' The Journal of Primary Prevention, 24(3): 325-334.

Pine, N. (2010). 'The role of athletics in the academy: An alternative approach to financial investment.' Journal of Sport and Social Issues, 34(4): 475-480.

Plowman, S. A., \& Smith, D. L. (2008). Exercise physiology for health, fitness and performance $\left(2^{\text {nd }}\right.$ ed.). Baltimore: Lippincott Williams \& Wilkins.

Ring, C., Carroll, D., Hoving, J., Ormerod, J., Harrison, L. K., \& Drayson, M. (2005). 'Effects of competition, exercise, and mental stress on secretory immunity.' Journal of Sports Sciences, 23(5): 501-508.

Rosenbaum, M. (1980). 'A schedule for assessing self-control behaviors: preliminary finding.' Behavior Therapy, 11: 109-121.

Shachaf, M. (2009). The relationship between high school students' participation in competitive sport, personality characteristics and academic achievement. RamatGan, IL:Unpublished doctoral dissertation, Bar-Ilan University (In Hebrew).

Shaffer, D. R., \& Wittes, E. (2006). 'Women's precollege sports participation, enjoyment of sports, and self-esteem.' Sex Roles, 55: 225-233.

Tangney, J. P., Baumeister, R. F., \& Boone, A. L. (2004). 'High self- control predicts good adjustment, less pathology, better grades, and interpersonal success.' Journal of Personality, 72(2): 271-324.

Thoresen, C. E., \& Mahoney, M. J. (1974). Behavioral self control. Austin, TX: Holt, Rinehart \& Winston Inc. 
van der Horest, K., Paw, M. J., Twisk, J. W., \& van Mechelen, W. (2007). 'A brief review on correlates of physical activity and sedentariness in youth.' Medicine and Science in Sport and Exercise, 39(8): 1241-1250

Weiner, B. (1980). 'A cognitive (attribution) - emotion- action model of motivation behavior. an analysis of judgments of help giving.' Journal of Personality of Social Psychology, 39: 186-200.

Wulf, G., \& Toole, T. (1999). 'Physical assistance devices in complex motor skill learning: Benefits of a self-controlled practice schedule.' Research Quarterly for Exercise and Sport, 70(3): 265-272.

Zeidner, M., Schwarzer, R., \& Jerusalem, M. (1993). 'Hebrew adaptation of General Self-Efficacy Scale.' Health Psychology, 12: 102-104. 
